ally with papillary microadenomas two patients or "Wilms' tumorlets" (three patients). In 3 of the 12 children another Nbl appeared in the contralateral kidney. Another patient, who died shortly after surgery, also had nephroblastomatosis in the remaining kidney. One patient was alive and healthy 3.5 years postoperation; another died with metastatic disease and autopsy was not performed, four were lost to follow-up, and in two nephrectomy is too recent for evaluation. The importance of careful examination of "uninvolved" parenchyma in Nbl is stressed in order to detect other nephropathies that may adversely influence prognosis, and to detect those children in high risk of developing bilateral tumors.

\section{Transportation and Accessibility to Medical Care in Am- bulatory Children with Renal Diseases}

JOSE GRUNBERG, ALBERTO SITKEWICH, NOEMIE ESQUIVEL, DELCIA SILVA Policlinica Nefrologica, Hospital Dr. P. Visca, Casilla 1138, Montevideo, Uruguay

The means of transportation from the interior of the country to the hospital in the capital, located in the southernmost part of the country, were considered in a prospective study held in the winter months for 65 unselected consecutive outpatient visits to the hospital of patients with chronic nephropathies. The bus was used for transportation in 50 cases, the railway in 13, and the car in 2 . Most of the patients had to use more than two vehicles. Fortythree children $(66.15 \%)$ traveled directly to the capital (group I) and 22 children $(33.8 \%)$ had to stay overnight for 1 or 2 nights (group II). Sixteen children of group I (3712\%) had to leave home at 5:30 am or earlier. The mean time for the whole trip to the hospital was $2: 25 \mathrm{hr}$ (range 1:10 hr to $6 \mathrm{hr}$ ) for group I and 22:15 hr (range 11:15 hr to 73:15 hr) for group II.

The ratio of patients to total population of the corresponding geographic areas (per 100,000) was: 8.84, 3.91, and 1.30 for the distance from home to hospital, 40 to 100,101 to 200 , and more than $200 \mathrm{~km}$, respectively. These ratios indicate that it is impossible for some children to travel to the capital.

For $56.9 \%$ of the families, the trip was very expensive; $35.9 \%$ of the families required financial help. Ten out of 62 families were known to have missed other appointments due to transportation and financial difficulties.

The negative impact of distance and transportation difficulties on clinic attendance by chronic outpatients might be reduced with more logical consultation hours, mail or telephone communications, and with medical care given by properly trained local physicians.

Even in small countries like Uruguay, without geographical ruggedness, transportation is one of the most important barriers to medical care.

\section{Protein Evaluation of Extrusion-cooked Sweet Lupine ( $\mathrm{Lu}$ - pinus albus)}

D. BALLESTER, $*$ F. SANCHEX, $\dagger$ AND E. YANEX* $*$ Instituto de Nutricion y Tecnologia de los Alimentos, Universidad de Chile, Casilla 15138, Santiago, Chile and †Instituto Tecnologico de Chile, INTEC, Santiago, Chile

In previous studies conducted by our group, it has been demonstrated that the beans of two species of sweet lupines (Lupinus luteus and Lupinus albus) contained about $40 \%$ protein, $11.5 \%$ of crude fiber and a low level of alkaloids ( $0.05 \%$ lupanine). This protein is poorly balanced due to its low methionine content. In this study, Lupinus albus beans were mechanically treated to reduce the fiber content from $11.5-2.7 \%$ and were divided into two portions. One was raw and the other was extrusion cooked in a Wenger X-25 extruder. Both were analyzed for their chemical composition, protein efficiency ratio (PER) and digestibility. The raw sample was found to contain about $40 \%$ protein $(\mathrm{N} \times 6.25)$ and $12 \%$ ether extract. These values were practically unchanged by processing. The protein efficiency ratio significantly increased in the cooked-extruded sample from $0.50 \pm 0.02$ to $0.76 \pm 0.05$. Supplementation of two samples with $0.3 \%$ DL-methionine increased the protein quality to values similar to casein (PER 2.60 \pm 0.05 compared with $2.54 \pm 0.07$ casein). Digestibility was not affected by extrusion cooking $(76.5 \pm 1.9$ and $77.8 \pm 0.7$ for raw and extruded-cooked samples, respectively). These results indicate that sweet lupine may become a valuable protein source for human or animal feeding provided that the deficiency of sulfurcontaining amino acids is corrected. Our work also highlights the advantage of extrusion cooking in the processing of this legume.

\section{Sociological Analysis of the Families of Severely Malnour- ished Children}

M. LUZ ALVAREZ, DORA MIKASIC, ANA OTTENBERGER, AND M. ESTER SALAZAR Instituto de Nutrition and Food Technology, University of Chile, Santiago, Chile

Malnourished infants in Chile receive comprehensive treatment through a Program of Nutritional Rehabilitation Centers, which involves not only the rehabilitation of the infants but also that of their families. This program is planned so that after discharge from the centers, children will continue developing normally within their home environment. A careful analysis of the basic socioeconomical and cultural characteristics of the families in which malnutrition occurs becomes a prerequisite for an accurate diagnosis and treatment of similar groups. The design of this study entails an in depth, descriptive analysis of the families and an investigation of the relationships that may exist among the variables studied. A sample of 42 families of greater Santiago was analyzed. All of them had infants admitted to a Nutritional Rehabilitation Center. A structured interview was administered to the mothers by specially trained social workers during the period from January through March 1977. It was found that: 1) a majority of mothers were under medical supervision during pregnancy; 2) the weight of the infants at birth was significantly greater than $2,500 \mathrm{~g} ; 3$ ) the duration of breast feeding was less than 1 month in $64.2 \%$ of cases; 4) $62 \%$ of the mothers had no knowledge of the normal parameters of infant development; 5) almost a quarter $(21 \%)$ of the families were classified as cases of extreme poverty. They provided very little sensory stimulation to their offspring, in part due to a very deficient physical home environment, 6) Verbal communication between the members of the household was very poor and hindered the rehabilitation of the patient and the family.

\section{Acute Chagas Disease in the Infant}

M. SANCHEZ, E. ZEGARRA, B. J. SATT, AND Y. CHAPUIS Centro de Pediatria "Albina R. De Patino," Cochabamba, Bolivia

Acute Chagas disease is greatly variable in its clinical manifestations. The acute stage is the most important, because the specific treatment has its best action in the acute stage. An early diagnosis is essential. In the last 7 years, in the Pediatric Center "Albina $R$. de Patino" 108 children have been hospitalized with acute Chagas, all of them with positive parasitology (thick drop, fresh drop, or Strout). An analysis has been done of the ages of the infants, the clinical manifestations of acute Chagas, the criteria for diagnosis, and experience in the use of the drug, Lampit (Nifurtimox). 